\title{
ASPECTOS FISIOLÓGICOS E CARACTERIZAÇÃO DA TOXIDEZ DE ÁCIDOS ORGÂNICOS VOLÁTEIS EM PLANTAS
}

\author{
PHYSIOLOGICAL ASPECTS AND CHARACTERIZATION OF \\ VOLATILE ORGANIC ACIDS TOXICITY ON PLANTS
}

\author{
Flávio Anastácio de Oliveira Camargo ${ }^{1}$ Everaldo Zonta $^{2}$ \\ Gabriel de Araújo Santos ${ }^{2}$ Roberto Oscar Pereyra Rossiello ${ }^{2}$
}

\section{- REVISÃo BIBLIOGRÁFICA -}

RESUMO

O manejo de resíduos orgânicos sob condições anaeróbias pode, durante a fase inicial do processo metabólico, levar à formação de ácidos orgânicos voláteis $\left(C_{l}-C_{4}\right)$, cuja atividade fitotóxica determina perdas substanciais à produção vegetal. A caracterização da fitoxidez desses ácidos foi o objetivo da presente revisão. O tipo e quantidade dos ácidos produzidos durante o processo dependem, basicamente, da quantidade e qualidade do resíduo adicionado, sendo a fitotoxidez diretamente relacionada ao comprimento da cadeia de carbonos e concentração dos ácidos e ao pH do meio em que se encontram. Os principais efeitos estão associados à inibição da germinação $e$ da expansão radicular, como resultado de lesões causadas ao tecido meristemático da radícula ou de limitações à respiração, conduzindo à inibição da divisão celular.

Palavras-chave: fitotoxidez, $\mathrm{pH}$, decomposição anaeróbia, matéria orgânica.

\section{SUMMARY}

Volatile organic acids $\left(C_{1}-C_{4}\right)$ can be build up during the first stages of metabolic process under anaerobic conditions of organic residues management. The phytotoxicity can leads to significant losses of crop production. The phytotoxicity of this acids was the aim of this revision. The type and amount of acids produced during the process are basically dependent on the amount and quality of the residue and the phytoxicity is directly related to the length of $C$ compounds, to the acid concentration, and to the soil solution $\mathrm{pH}$. The main effects, as germination inhibition and root expansion, are related to damaged root meristematic tissue or respiration inhibition and consequently leading to inhibition of cell division.
Key words: phytoxicity, $p H$, anaerobic decomposition, organic matter.

\section{INTRODUÇÃO}

A incorporação de resíduos culturais ao solo antes de um novo plantio sofre potencialmente a desvantagem de que produtos fitotóxicos, oriundos do metabolismo do material orgânico incorporado, possam exercer efeitos negativos, limitando a germinação e o estabelecimento das plântulas (CAMARGO, 1992). Em condições anaeróbias, o problema é mais agravante, dada a baixa eficiência metabólica microbiana na conversão do carbono adicionado, levando a acumulação de compostos que afetam, de forma irreversível, a produtividade final das culturas estabelecidas nesse sistema (CAMARGO $\boldsymbol{e} \boldsymbol{t} \boldsymbol{a l}$., 1995a; BRANCHER $\boldsymbol{e} \boldsymbol{t} \boldsymbol{a l}$. 1996a).

Dos numerosos compostos formados pelo metabolismo anaeróbio, destacam-se os ácidos orgânicos, especialmente os ácidos alifáticos de cadeia curta, como o fórmico, o acético, o propiônico e o butírico (STEVENSON, 1967), que ocorrem, usualmente, na faixa de concentração de 0,1 a $10 \mathrm{mmo} \ell \mathrm{L}^{-1}$. Dada a sua volatilidade, possuem curta vida média na solução, porém, são produzidos de forma contínua pela reciclagem microbiana

\footnotetext{
${ }^{1}$ Professor do Departamento de Solos, Faculdade de Agronomia, Universidade Federal do Rio Grande do Sul, CP 776, 90001-970, Porto Alegre, RS. Autor para correspondência. E-mail: fcamargo@vortex.ufrgs.br.

${ }^{2}$ Professor do Departamento de Solos, Instituto de Agronomia, Universidade Federal Rural do Rio de Janeiro, Antiga rodovia Rio/SP, km 47, 23840-970, Itaguaí, RJ.
} 
(SPOSITO, 1989). O tipo e a quantidade dos ácidos produzidos durante o processo, dependem, basicamente, da quantidade e qualidade do resíduo orgânico adicionado, da característica fermentativa da microbiota e das condições predominantes no solo (CAMARGO et $\boldsymbol{a l}$., 1993a). A acumulação desses ácidos no solo afeta diretamente algumas culturas, principalmente pela inibição da respiração (ROBSON \& TAYLOR, 1974), levando à diminuição no alongamento radicular (CAMARGO et al., 1993b) e na absorção de nutrientes (RAO \& MIKKELSEN, 1976, 1977ab; CAMARGO et al., 1995b).

A fitoxidez dos ácidos orgânicos é dependente do $\mathrm{pH}$. Em solos alagados, o $\mathrm{pH}$ tende à neutralidade após as primeiras semanas de submergência (CAMARGO et al., 1999), onde deve predominar a forma não dissociada deles, a qual é considerada inofensiva às plantas (HARPER \& LYNCH, 1981). Esse raciocínio está correto em relação à massa global do solo livre de raízes, porém, negligencia a situação real na rizosfera radicular. Com efeito, sendo $\mathrm{NH}_{4}^{+}$a forma de $\mathrm{N}$ predominante nesses solos, a sua absorção radicular causa um desbalanço de cátions em relação aos ânions absorvidos, o que é compensado pela extrusão ativa de $\mathrm{H}^{+}$, causando gradientes marcantes de acidez entre a rizosfera e a massa do solo livre das raízes, tal como mostrado em arroz, milho e outras culturas (FERNANDES et al., 1981; FERNANDES \& ROSSIELLO, 1986). Dessa forma, o valor do $\mathrm{pH}$ no espaço livre radicular pode ser 1 a 2 unidades menor do que na massa de solo (HARPER \& LYNCH, 1981; FERNANDES \& ROSSIELLO, 1986). Essa variação de $\mathrm{pH}$ pode ser responsável pela fitoxidez decorrente da presença de ácidos orgânicos em solos com pH neutro, cultivados com arroz (CHANDRASEKARAN \& YOSHIDA, 1973).

A necessidade de estudos a respeito do comportamento e efeito dos metabólitos produzidos pela decomposição anaeróbia de material orgânico é verificada pela deficiente bibliografia existente, bem como pela ausência de informações a respeito do manejo da toxidez sob tais condições. Desse modo, procurou-se, no presente trabalho, abordar aspectos relacionados à ocorrência e distribuição de ácidos orgânicos voláteis no solo e as implicações fisiológicas da fitoxidez desses metabólitos.

\section{Ocorrência e distribuição de ácidos orgânicos voláteis}

A matéria orgânica do solo origina-se da deterioração de organismos vivendo em, ou, no solo, e de uma variedade de compostos derivados desses organismos, bem como da adição de resíduos de origem vegetal e animal. Na fase orgânica do solo, tem sido isolado e identificado numerosos compostos (FLAIG, 1971; STEVENSON, 1994), que podem em uma aproximação mais grosseira, ser classificados em humificados e não humificados. Os compostos humificados são produzidos durante o processo de decomposição dos constituintes não humificados, e consistem de um grupo de compostos complexos e estáveis como ácido fúlvico e ácido húmico e os derivados do ácido benzóico. A formação deste último composto processa-se durante a degradação oxidativa dos compostos húmicos. As substâncias não humificadas podem ser liberadas pela decomposição do tecido animal, vegetal ou microbiano em suas formas originais ou ligeiramente modificadas. Essas formas incluem carboidratos, aminoácidos, pigmentos, hormônios e uma variedade de ácidos orgânicos. Estes últimos podem estender-se desde simples ácidos alifáticos até complexos aromáticos e heterocíclicos (TAN, 1986).

Ácidos orgânicos voláteis alifáticos monocarboxílicos de cadeia curta e baixo peso molecular tais como fórmico, acético, propiônico e butírico $\left(\mathrm{C}_{1}\right.$ a $\left.\mathrm{C}_{4}\right)$ são os principais produtos da decomposição anaeróbia da matéria orgânica (Tabela 1). Entre esses ácidos, o acético é geralmente o principal ácido orgânico formado no processo. LYNCH (1976) verificou que o ácido acético era responsável por $63 \%$ da composição dos ácidos orgânicos produzidos na decomposição de celulose por microrganismos anaeróbios termofílicos. De modo geral, materiais orgânicos de fácil decomposição produzem maiores quantidades de ácidos do que materiais mais resistentes (TAKAI et al., 1963; HARPER \& LYNCH, 1981).

A palha de arroz é um material orgânico comumente adicionado ao solo pela colheita, sendo mais resistente à decomposição do que estercos e materiais mais concentrados em carboidratos. Em solos inundados, há indicações, quando da presença de palha, de produção de ácido acético significativamente mais elevada do que ácido butírico (Tabela 1). Observa-se, na tabela 1 , que o pico máximo de produção desses metabólitos ocorre em torno da segunda semana após a incorporação da palha e, em menos de uma semana, para materiais mais facilmente decomponíveis.

\section{Sintomas relacionados à toxidez}

$\mathrm{Na}$ cultura do arroz, após aplicação de 56 t.ha ${ }^{-1}$ de palha e esterco foi verificada uma elevada percentagem de esterilidade na panícula, manifestando os sintomas visíveis da doença "bico de papagaio" (BRANCHER et al., 1996a). Essa deno-

Ciência Rural, v. 31, n. 3, 2001. 
Tabela 1 - Distribuição de ácidos orgânicos voláteis após a incorporação de materiais orgânicos no solo.

\begin{tabular}{|c|c|c|c|c|c|c|c|}
\hline \multicolumn{2}{|c|}{ Materiais orgânicos } & \multicolumn{5}{|c|}{ Ácidos orgânicos voláteis } & \multirow[b]{2}{*}{ Referências } \\
\hline Tipo & Quantidade & Acético & Propiônico & Butírico & Outros & Total & \\
\hline & $-\mathrm{mg} / \mathrm{kg}-$ & ------------ & -------- mmo & $1 . \mathrm{kg}^{-1}$ & - & ------- & \\
\hline Astragalus sinicus & 30 & $9,4(7)$ & & & $3,9(4)$ & $12,7(7)$ & TAKIJIMA \& SAKUMA (1961) \\
\hline Astragalus sinicus & 35 & $8,9(14)$ & & & $1,0(14)$ & $11,1(14)$ & $"$ \\
\hline Astragalus sinicus & 52 & $16,0(7)$ & & & $1,5(14)$ & $20,6(7)$ & $"$ \\
\hline Astragalus sinicus & 69 & $29,0(4)$ & & & $3,1(7)$ & $36,0(4)$ & $"$ \\
\hline Palha de arroz & 100 & $14,0(14)$ & $1,3(28)$ & $4,8(3)$ & & $16,2(14)$ & GOTO \& ONIKURA (1967) \\
\hline Palha de trigo & 100 & $9,2(14)$ & & & $1,3(14)$ & $10,5(14)$ & $"$ \\
\hline Capim italiano & 100 & $5,9(14)$ & & & $0,3(14)$ & $6,3(14)$ & $"$ \\
\hline Composto & 100 & $0,6(14)$ & & & $0,1(14)$ & $0,8(14)$ & $"$ \\
\hline Folha de Sesbania & 2500 & $43,8(5)$ & $1,3(5)$ & $4,8(3)$ & & & CHANDRASEKARAM \& YOSHIDA (1973) \\
\hline Palha de arroz & 5000 & $13,3(14)$ & $3,8(21)$ & & & & RAO \& MIKKELSEN (1976) \\
\hline Resíduos culturais & 22400 & $10,0(3)$ & $2,0(3)$ & $0,6(3)$ & & & FU \& TABATABAI (1988) \\
\hline Palha de trigo & 10000 & $14,45(14)$ & $1,56(14)$ & $0,1(14)$ & & & PAUL \& BEAUCHAMP (1989) \\
\hline Palha de arroz & 20000 & & & & & $36,4(14)$ & SHARMA et al. (1989) \\
\hline Palha de arroz & 2500 & & & & & $5,4(1)$ & CAMARGO et al. (1993b) \\
\hline Palha de arroz & 5000 & & & & & $7,5(7)$ & $"$ \\
\hline Palha de arroz & 10000 & & & & & $8,0(1)$ & $"$ \\
\hline Palha de arroz & 20000 & & & & & $14,7(1)$ & $"$ \\
\hline Grama de Ponta & 10000 & $1,0(28)$ & & & $0,8(28)$ & $1,8(28)$ & BAZIMAKENGA et al. (1995) \\
\hline Azevém & 5000 & $33,3(28)$ & $5,7(28)$ & $5,4(28)$ & $0,8(28)$ & $45,2(28)$ & SOUZA et al. (2000) \\
\hline
\end{tabular}

Os números entre parênteses indicam os dias após a inundação, no qual foram feitas as determinações analíticas.

minação é dada em função das características morfológicas do grão atacado, ou seja, a lema cresce mais do que a palea e curva-se sobre esta, dando a forma de um bico (PEDROSO, 1985). Os sintomas se manifestam também sobre a rizosfera que apresenta um maior volume de raízes grosseiras, com algumas ramificações e pouco pelos radiculares e sobre a planta, que tende a emitir ramificações a partir dos nós inferiores, que por definição seriam perfilhos axiais (BRANCHER et al., 1996a). Essa doença foi descrita como resultante de um múltiplo estresse nutricional causado, em última análise, por excessos de material orgânico em decomposição sob condições anaeróbias.

BABA et al. (1965) observaram a ocorrência de doença similar no Japão, ou seja, uma extrema esterilidade nas flores, chamada "hideriaodachi" e com a mesma deformação de espiguetas descrita anteriormente. Sintomas e manejo semelhantes são também descritos para a doença fisiológica "straighthead" (BABA et al., 1965). "Straigthead" é o sintoma de uma condição fisiológica que pode ser devido a várias causas. Sob vários nomes, ela ocorre em vários países e algumas vezes conduz a perdas significativas da produção de arroz. Além dos sintomas relacionados, a ausência do pistilo das flores afetadas, o que conduz à esterilidade, as folhas e caules apresentam coloração verde escura e consistência rígida, sendo em alguns casos extremos, toda a planta afetada com várias anormalidades nas folhas e orgãos sexuais (BRANCHER et al., 1996a).

A causa exata dessa doença é desconhecida, mas acredita-se que as desordens relacionadas podem estar associadas a condições desfavoráveis do solo, agravadas pelo alagamento contínuo. Nesse sistema, as doenças fisiológicas mais comuns que atacam a cultura do arroz são atribuídas à formação de ácidos orgânicos voláteis, ácido sulfídrico e altas concentrações de ferro reduzido (BRANCHER $\boldsymbol{e t}$ al., 1996b), pois quando as raízes são expostas a essas toxinas, elas são danificadas e suas funções fisiológicas obstruídas (TAKIJIMA, 1965). Entretanto, existem situações em que se verificam a presença de microsítios anaeróbios em ambiente aeróbio que podem levar à manifestação da toxidez de ácidos orgânicos em outras culturas que não o arroz, principalmente em situações de adição de resíduos ao solo, como no caso do plantio direto na palha que acumula, geralmente, uma maior umidade (CHOU \& YOUNG, 1975; LYNCH, 1976; TANG \& WAISS, 1978).

Em termos práticos, os prejuízos relacionados à toxidez de ácidos orgânicos estão associados à presença de material orgânico decompondo-se em condições de anaerobiose. Assim, é possível verifi-

Ciência Rural, v. 31, n. 3, 2001. 
car citações a respeito de diminuições no número de perfilhos de arroz irrigado (ANSUS \& REIS, 1979), altura das plantas, número de perfilhos e de panículas (GOTO \& ONIKURA, 1971) e do rendimento de grãos e de palhada (CAMARGO et al., 1995a). Como a maior produção de ácidos ocorre na fase inicial do plantio, os efeitos descritos podem estar mais intimamente relacionados à fase de germinação de sementes, como o caso da cevada que apresentou uma inibição pelo ácido acético de $77 \%$ da germinação (LYNCH, 1980) do trigo (22\% de germinação quando se testou o ácido acético, e nenhuma semente germinada quando se testaram os ácidos propiônico e butírico), do milho (56\% de germinação quando se testou o ácido butírico) e da cevada (35\% de germinação quando se testou o ácido propiônico e $12 \%$ quando se testou o ácido butírico) (KROGMEIER \& BREMNER, 1990). Na fase subseqüiente de plântula, verifica-se um número maior de referências a respeito do efeito negativo de ácidos orgânicos sobre o alongamento radicular da cultura do arroz (TAKIJIMA, 1964; RAO \& MIKKELSEN, 1977a; RAO \& MIKKELSEN, 1977b; CAMARGO et al., 1993b) da cevada (LYNCH, 1978; LYNCH, 1980; KROGMEIER \& BREMNER, 1990), do trigo (LYNCH, 1978; TANG \& WAISS, 1978; WALLACE \& EELLIOTT, 1979; LYNCH, 1980; WALLACE \& WHITHEAD, 1980; KROGMEIER \& BREMNER, 1990), do milho (LYNCH, 1980; KROGMEIER \& BREMNER, 1990), da aveia (LYNCH, 1978) e do trevo (LYNCH, 1980). A maioria desses autores relatam, ainda, o efeito desses ácidos sobre o peso e altura de plântulas, bem como sobre a produção de matéria seca de raízes. Além desses parâmetros, o comprimento e área radicular foram citados, em termos de redução relativa, como os mais afetados (60 e 66\%, respectivamente) pelos ácidos acético e butírico (CAMARGO et al., 1993b). Esses autores observaram, ainda, que os efeitos acentuados do ácido butírico sobre a área radicular total permitem supor que esse parâmetro seja de maior relevância para avaliação da fitoxidez de ácidos de maior comprimento de cadeia.

Esses ácidos interferem, entre outros efeitos, na absorção de nutrientes, principalmente, na cultura do arroz irrigado (CAMARGO et al., 1993b). TAKIJIMA et al. (1960) observaram que concentrações acima de $1 \mathrm{mmo} \ell \mathrm{L}^{-1}$ de ácido acético reduziram a absorção de $\mathrm{P}, \mathrm{K}$ e Si dessa cultura. A redução nos teores de $\mathrm{K}$ foi significativa em presença de ácido butírico e acima de $40 \mathrm{mmo} \ell \mathrm{L}^{-1}$ de ácido acético (TANAKA \& NAVASERO, 1967). Esse efeito deletério foi verificado na faixa de 0,0 a $0,2 \mathrm{mmo} \ell \mathrm{L}^{-1}$ de ácido butírico, reduzindo a absorção de $\mathrm{K}, \mathrm{P}, \mathrm{NH}_{4}, \mathrm{Mn}, \mathrm{Mg}$ e $\mathrm{Ca}$, de forma mais acentuada que outros inibidores estudados (MITSUI et al., 1954). Em geral, ácidos alifáticos monocarboxílicos de baixo peso molecular inibem a absorção de nutrientes, principalmente $\mathrm{K}, \mathrm{P}, \mathrm{Ca}, \mathrm{Mn}, \mathrm{Mg}$ e $\mathrm{Si}$ (MITSUI, 1960; BABA et al., 1965).

\section{Aspectos fisiológicos da toxidez}

A fitoxidez de ácidos orgânicos voláteis está diretamente relacionada ao tipo e concentração de ácido e ao pH da solução em que se encontram (RAO \& MIKKELSEN, 1977b; LYNCH, 1980; CAMARGO et al., 1993b). Esses autores verificaram que o alongamento radicular era o principal indicador dos efeitos inibidores provocados pelos ácidos orgânicos, e que aumentam a sua fitoxidez conforme aumentam a concentração e o comprimento da cadeia de carbono (Figura 1). Observaram, ainda, que a redução do tamanho do sistema radicular foi acompanhada pela inibição da iniciação de novas raízes.

Como mencionado anteriormente, a fitoxidez dos ácidos é dependente do $\mathrm{pH}$. Considerando-se a constante de dissociação $(\mathrm{pK})$ do ácido acético, verifica-se que a $\mathrm{pH} 4,0$, sua nãodissociação é de $85 \%$, enquanto que a pH $6,5,95 \%$

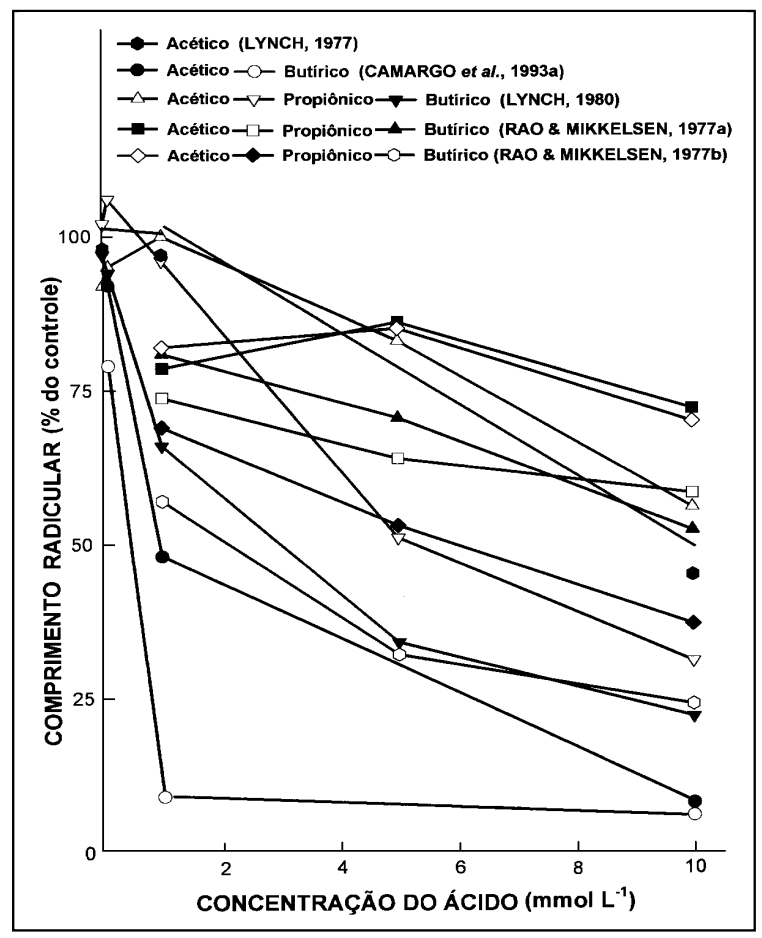

Figura 1 - Efeito de ácidos orgânicos voláteis sobre a expansão radicular de plântulas cultivadas em solução nutritiva.

Ciência Rural, v. 31, n. 3, 2001. 
do mesmo encontra-se como acetato (LYNCH, 1980). Portanto, o decréscimo do $\mathrm{pH}$, levando ao aumento da forma não dissociada, determina um aumento da lipossolubilidade dos ácidos, nos componentes lipídicos da membrana, aumentando nela a permeabilidade, ou, de outra forma, diminuindo o seu coeficiente de reflexão (TANAKA \& NAVASERO, 1967). Poderia ser esperado, por essas razões, que um valor baixo de $\mathrm{pH}$ resultasse mais fitotóxico como mostra a figura 2. MOLONEY et al. (1981) estudaram a resposta de segmentos apicais de raízes de milho em termos de porcentagem de extensão, quando expostas a soluções-tampão (fosfato-citrato, $10^{-3} \mathrm{mo} \ell \quad \mathrm{L}^{-1}$ ) ajustadas a valores de $\mathrm{pH}$ entre 3 e 8 . Esses autores observaram que houve estimulação máxima entre pH 4 e 5 , com a porcentagem de extensão caindo rapidamente fora desses limites. No presente caso, tal tendência não se verifica, pois existe uma relação linear claramente expressa entre o comprimento radicular e pH (Figura 2). O mesmo tipo de relação foi obtida ao se considerar o comprimento da parte aérea.

De modo geral, esses efeitos podem ser o resultado de lesões causadas ao tecido meristemático

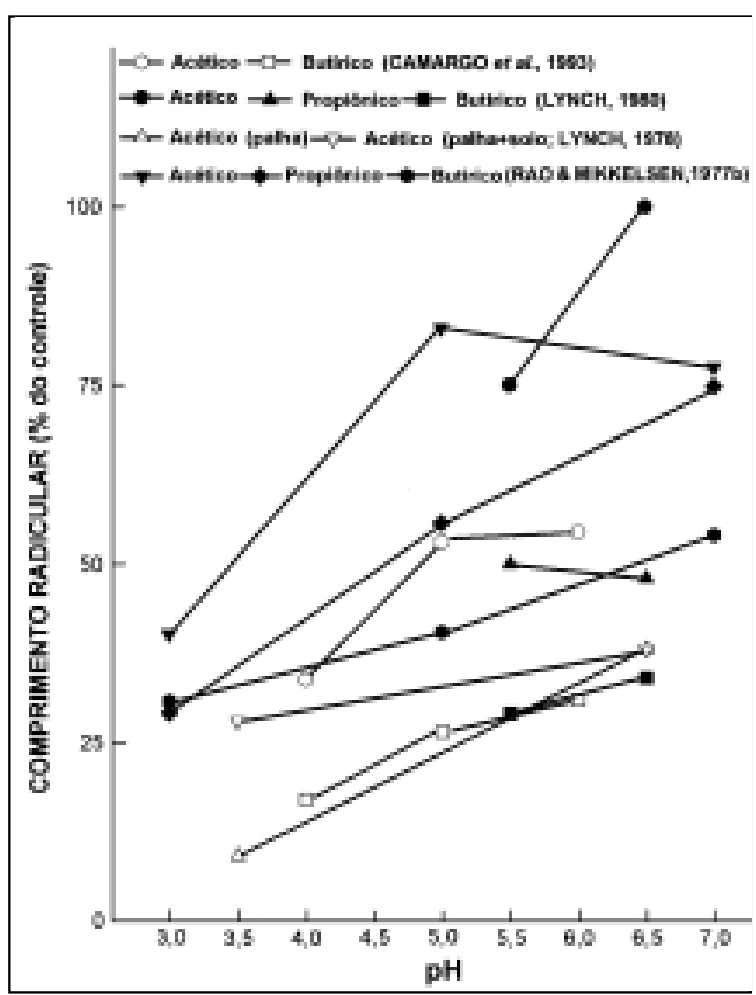

Figura 2 - Efeito de níveis de $\mathrm{pH}$ sobre a expansão radicular de plântulas cultivadas em solução nutritiva, na presença de ácidos orgânicos voláteis. da radícula (CHOU \& PATRICK, 1976) ou de inibição à respiração (ROBSON \& TAYLOR, 1974), o que deve resultar em inibição da divisão celular. Por outro lado, essas fitoxinas são inibidores marcantes de funções mitocondriais, incluindo o desacoplamento da fosforilação oxidativa, assim como do transporte de metabólitos e de enzimas glicolíticas solúveis no citossol, e as ligadas a endomembranas, como as responsáveis pela síntese de polissacarídeos e a ATPase (RADAMOS et al., 1976; WOJTCZACK, 1976; MORRÉ \& MOLENHAUER, 1976; CHAN \& HIGGINS, 1978).

LEE (1977) verificou que ácidos orgânicos causaram o efluxo de íons inorgânicos e material orgânico para o meio externo, o que implica a danificação da integridade da plasmalema. O efeito combinado desses processos inibitórios deve conduzir a uma marcada redução do acúmulo vacuolar de solutos necessários ao influxo osmótico de água, responsável pela manutenção de turgescência positiva nas células. Geração de energia metabólica e funcionalidade da ATPase ligada à membrana celular são pré-requisitos para esse processo (FERNANDES \& ROSSIELLO, 1986). A perda de turgescência subseqüente interrompe, então, o estímulo básico à extensão da parede celular, e bloqueia os mecanismos de biossíntese responsáveis pela deposição de novo material estrutural na parede (TAIZ, 1984).

\section{CONCLUSÕES}

Produtos intermediários da decomposição do material orgânico do solo podem acumular-se no solo e afetar negativamente o desenvolvimento de plantas. Em condições anaeróbias, os problemas são mais agravantes devido à acumulação de ácidos orgânicos voláteis alifáticos, monocarboxílicos e de cadeia curta. O efeito fitotóxico é dependente do comprimento da cadeia de carbonos e concentração desses ácidos, bem como, do pH da solução em que se encontram. O sistema radicular, na fase inicial do crescimento vegetal, é a estrutura mais afetada, principalmente, o alongamento e a emissão de pêlos radiculares. Esses sintomas estão associados à inibição à respiração, com conseqüente inibição da divisão celular.

\section{REFERÊNCIAS BIBLIOGRÁFICAS}

ANSUS, A.A.J., REYS, P.L. The effect of rice straw on the growth Tiller production, and yield of transplanted rice. Araneta Research Journal, Bangladesh, v.26, n.1/2, p.28-46, 1979.

BABA, I., INADA, K., TAKIJIMA, K. Mineral nutrition and the occurence of physiological disease. In: IRRI. The mineral nutrition of rice plant. Baltimore : The John Hopkins, 1965. Cap.12, p.173-195.

Ciência Rural, v. 31, n. 3, 2001. 
BAZIRAMAKENGA, R., SIMARD, R.R., LEROUX, G.D. Deternination of organic acids in soil extracts by ion chromatography. Soil Biology and Biochemistry, Oxford, v.27, 349-356, 1995.

BRANCHER, A., CAMARGO, F.A.O., SANTOS, G.A. Occurrence of physiological disease in flooded rice fields. Ciência Rural, Santa Maria, v.26, n.1, p.149-151, 1996a.

BRANCHER, A., CAMARGO, F.A.O., SANTOS, G.A. Efeito da adubação orgânica, mineral e calagem no acúmulo de ferro pelo arroz irrigado. Pesquisa Agropecuária Gaúcha, Porto Alegre, v.2, n.1, p.101-106, 1996b.

CAMARGO, F.A.O. Caracterização da ação fitotóxica de ácidos orgânicos voláteis sobre a cultura do arroz. Itaguaí - RS, 1992. 126p. Dissertação (Mestrado em Agronomia) Curso de Pós-graduação em Agronomia, Universidade Federal Rural do Rio de Janeiro, 1992.

CAMARGO, F.A.O., SANTOS, G.A., ROSSIELLO, R.O.P., $\boldsymbol{e}$ al. Produção de ácidos orgânicos voláteis pela planta de arroz sob condições anaeróbias. Revista Brasileira de Ciência do Solo, Campinas, v.17, n.3, p.337-342, 1993a.

CAMARGO, F.A.O., SANTOS, G.A., ROSSIELlO, R.O.P. Efeito dos ácidos acético e butírico sobre o crescimento de plântulas de arroz. Pesquisa Agropecuária Brasileira, Brasília, v.28, n.9, p.1011-1018, 1993b.

CAMARGO, F.A.O., SANTOS, G.A., ROSSIELLO, R.O.P., et al. Incorporação de palha de arroz em um gleissolo e efeitos no rendimento da cultura do arroz irrigado. Pesquisa Agropecuária Brasileira, Brasília, v.30, n.7, p.983-987, $1995 \mathrm{a}$

CAMARGO, F.A.O., SANTOS, G.A., ROSSIELLO, R.O.P., et al. Acúmulo de nutrientes pelo arroz influenciado pela incorporação de palha em gleissolo. Revista Brasileira de Ciência do Solo, Campinas, v.19, n.2, p.243-247, $1995 b$

CAMARGO, F.A.O., SANTOS, G.A., ZONTA, E. Alterações eletro-química em solos inundados. Ciência Rural, Santa Maria, v.29, n.1, p.171-180, 1999.

CHAN, S.H.P., HIGGINS, E. Uncoupling activity of endogenous free fatty acids in rat liver mitochondria. Canadian Journal of Biochemistry, Otawa, v.56, p.111-116, 1978

CHANDRASEKARAN, S., YOSHIDA, T. Effect of organic acid transformation in submerged soil on the growth of the rice plant. Soil Science and Plant Nutrition, Tokyo, v.19, p.39$45,1973$.

CHOU, C.H., PATRICK, Z.A. Identification and phytotoxic acativity of compounds produced during decomposition of corn and rye residues in soil. Journal of Chemistry and Ecology, New York, v.2, n.3, p.369-383, 1976.

CHOU, C.H., YOUNG, C.C. Phytotoxic substances in twelve subtropical grasses. Journal of Chemistry and Ecology, New York, v.1, n.2, p. 183-193, 1975.

FLAIG, W. Organic compounds in soil. Soil Science, Baltimore, v.111, p.19-33, 1971

FERNANDES, M.S., DIDONET, H.R., ROSSIELLO, R.O.P. Resposta de quatro cultivares de arroz à aplicação de nitrogênio amoniacal com um inibidor de nitrificação.
Pesquisa Agropecuária Brasileira, Brasília, v.16, n.3, p.303-311, 1981.

FERNANDES, M.S., ROSSIELLO, R.O.P. Aspectos do metabolismo e utilização do nitrogênio em gramíneas tropicais In: MATTOS, H.B., WERNER, I.C., YAMADA, et al. (eds) Calagem e adubação de pastagens. [S.1]: Assoc. Bras. Pesquisa da Potassa e do Fosfato, 1986. p.93-123.

FU, M.H., TABATABAI, M.A. Determination of organic acids in soils by high performace liquid chromatography. Agronomy Abstracts, New York, p.197, 1988.

GOTOH, S., ONIKURA, Y. Organic acid in paddy soil. I. The production of organic acids in waterlogged soil in the presence of organic mater under laboratory condition. Bulletin of Kyushu Agricultural Experimental Station, Fukuoka, v.12, 235-249, 1967

GOTOH, S., ONIKURA, Y. Organic acids in flooded soil receiving added rice straw and their effect on the growth of rice. Soil Science and Plant Nutrition, Tokyo, v.17, n.1, p.1-8, 1971

HARPER, S.H.T., LYNCH, J.M. The chemical components and decomposition of wheat straw leaves, internodes and nodes. Journal of Science of Food and Agriculture, Baltimore, v.32, p.1057-1062, 1981

KROGMEIER, M.J., BREMNER, J.M. Effects of aliphatic acids on seed germination and seedling growth in soil. Communications in Soil Science and Plant Analysis, New York, v.21, n.7\&8, p.547-555, 1990.

LEE, R.B. Effects of roganic acids on the loss of ions from barley roots. Journal of Experimental Botany, New York, v.28. p.578-587, 1977

LYNCH, J.M. Products of soil microorganisms in relation to plant growth. CRC-Critical Reviews in Microbiology, New York, v.5, n.1, p.67-107, 1976

LYNCH, J.M. Production and phytotoxicity of acetic acid in anaerobic soils containing plant residues. Soil Biology and Biochemistry, Oxford, v.10, p.133-135, 1978.

LYNCH, J.M. Effects of organic acids on the germination of seeds and growth of seedling. Plant, Cell and Environment, London, v.3, p.255-259, 1980

MITSUI, S.K.K. Inorganic nutrition fertilization and soil amelioration for lowland rice. Tokyo : Yokendo, 1960 $107 \mathrm{p}$.

MITSUI, S.K.K., AJO, S., KUMASAWA, K., ISHIWARA, T. The nutrient uptake of rice plant influenced by $\mathrm{H}_{2} \mathrm{~S}$ and butyric acid abundantly evolued under water-logged soil conditions. Soil Science, Baltimore, v.5, p.367-368, 1954.

MOLONEY, M.M., ELliOT, M.C., CLELAND, R.E. Acid growth effects in maize roots: evidence for a link between auxin-economy and proton extrusion in the control of root growth. Planta, v.152, p.285-291, 1981

MORRÉ, D.I., MOLLEUNHAUER, H.H. Interaction among cytoplasm, endomembranes an the cell surface. In: STOCKING, C.R., HEBER, U. (eds). Encyclopedia of plant physiology: transport in plants. Berlin : SpringerVerlag, 1976. p.228-334.

Ciência Rural, v. 31, n. 3, 2001. 
PAUL, J.W., BEAUCHAMP, E.G. Rapid extraction and analysis of volatile fatty acids in soil. Communications in Soil Science and Plant Analysis, New York, v.20, n.1/2, p.85-94, 1989.

PEDROSO, B.A. Arroz irrigado. Obtenção e manejo de cultivares. 2.ed. Porto Alegre : Sagra, 1985. 175p.

RADAMOSS, C.S., UYEDA, K., JOHNSTON, J.M. Studies on the fatty acid inactivation of phosphofrutokinase. Journal of Biology Chemistry, New York, v.251, n.1, p.98-107, 1976.

RAO, D.N., MIKKELSEN, D.S. Effect of rice straw incorporation on rice plant growth and nutrition. Agronomy Journal, Madison, v.68, n.5, p.752-755, 1976.

RAO, D.N., MIKKELSEN, D.S. Effect of acetic, propionic, and butyric acids on young rice seedlings growth. Agronomy Journal, Madison, v.69, n.6, p.923-928, 1977a.

RAO, D.N., MIKKELSEN, D.S. Effects of acetic, propionic, and butyric acids on rice seedlings growth and nutrition. Plant and Soil, The Hague, v.47, p.323-334, 1977b.

ROBSON, T.W., TAYLOR, A.B. Effect of acetic acid on the respiration of parts of oat seedlings. American Journal of Botany, New York, v.28, n.10, p.135, 1974

SHARMA, P.K., DE DATTA, S.K., REDULLA, C.A. Effect of percolation on nutrient kinetics and rice yield in tropical rice soils. Plant and Soil, The Hague, v.119, p.121-126, 1989.

SOUSA, R.O., PERALBA, M.C.R., MEURER, E.J., et al . Ácidos orgânicos em solos alagados. In: REUNIÃO SUL BRASILEIRA DE CIÊNCIA DO SOLO, 3., 2000, Pelotas, RS. Resumos... Pelotas : NRS-SBCS, 2000. (no prelo).

SPOSITO, G. The chemistry of soils. Oxford : Orford University, 1989. 222p.

STEVENSON, F.J. Organic acids in soil. In: McLAREN, A.D., PETERSON, G.H. (eds). Soil biochemistry. Arnold : [s.n.], 1967. p.119-146.

STEVENSON, F.J. Humus chemistry genesis composition and reactions. 2.ed. New York : Jonh Willey \& Sons, 1994. 4943p.

TAN, K.H. Degradation of soil minerals by organic acids. In: HUANG, P.M., SCHNITZER, M. (eds). Interactions of soil minerals with natural organics and microbes. Madison : Soil Science Society of America, 1986. p.1-25.
TANAKA, A., NAVASERO, S.A. Carbon dioxide and organic acids in relation to the growth of rice. Soil Science and Plant Nutrition, Tokyo, v.13, p.25-30, 1967.

TAKAI, T., KOYAMA, T., KAMURA, T. Microbial metabolism in reduction process of paddy soils. Part 2. Effect of iron and organic matter on the reduction process. Soil Science and Plant Nutrition, Tokyo, v.9, p.176-180, 1963.

TAIZ, L. Plant cell expansion: regulation of cell wall mechanical properties. Annual Review of Plant Physiology, New York, v.35, p.585-657, 1984

TAKIJIMA, Y. Studies on organic acids in paddy field soils with reference to their inhibitory effects on the growth of rice plants. Part 1. Growth inhibiting action of organic acids and absorption and decomposition of them by soils. Soil Science and Plant Nutrition, v.10, p.14-21, 1964.

TAKIJIMA, Y. Studies on the mecanism of root damage of rice plants in the peat paddy fields. Part 2. Status of roots in the rhizosphere and the occurence of root damage. Soil Science and Plant Nutrition, v.11, p.20-27, 1965.

TAKIJIMA, Y., SHIOJIMA, M., ARITA, Y. Metabolism of organic acids in soils and their harmful effects on paddy growth. II. Effect of organic acids on root eleongation and nutrient absorption of rice plants. Journal of Science Plant Manure, Tokyo, v.31, n.3, p.441-446, 1960.

TAKIJIMA, Y., SAKUMA, H. Production of organic acids in waterllogged soil-treated with green manure (Chinese milk vetch) and its relation to growth inhibition of rice seedlings. Journal of Science Soil Manure, Tokyo, v.32, p.559-564, 1961.

TANG, C.S., WAISS, A.C. Short-chain fatty acids as groth inhibitors in decomposing wheat straw. Journal of Chemistry and Ecology, New York, v.4, n.2, p.225-232, 1978 .

WALLACE, J.M., WHITEHAND, L.C. Adverse synergistic effects between acetic, propionic, butyric and valeric acids on the growth of wheat seedling roots. Soil Biology and Biochemistry, Oxford, v.12, p.445-446, 1980.

WALLACE, J.M., ELLIOTT, L.F. Phytoxins from anaerobically decomposing wheat straw. Soil Biology and Biochemistry Oxford, v.11, p.325-330, 1979.

WOJTCZAK, L. Effects of long-chain fatty acids on Acyl-CoA on mitochondrial permeability, transport, and energycoupling processes. Journal of Bioenergetics of Biomembranes, London, v.8, n.2, p.293-311, 1976.

Ciência Rural, v. 31, n. 3, 2001. 